\title{
Early Relapse of Acute Myeloid Leukemia
}

National Cancer Institute

\section{Source}

National Cancer Institute. Early Relapse of Acute Myeloid Leukemia. NCI Thesaurus.

Code C123403.

Clinical and/or laboratory evidence of reemergence of acute myeloid leukemia less than 12 months from diagnosis. 